\title{
Prevalence of Multidrug-Resistant Tuberculosis at a Regional Drug-Resistant Tuberculosis Center of Maharashtra
}

\author{
Gauri Suhas Kulkarni, Supriya Dhakne Palwe', Nilesh P. Patil' Abhijit J. Telkhade'2, Jui Kadukar² \\ Department of Respiratory Medicine, Dr. Vasantrao Pawar Medical College, Hospital and Research Centre, Departments of ${ }^{1}$ Community Medicine and ${ }^{2}$ Respiratory \\ Medicine, Dr. Vasantrao Pawar Medical College, Nashik, Maharashtra, India
}

\section{Abstract}

Introduction: Multidrug-resistant tuberculosis (MDR-TB) has created a significant health problem in most of the countries, and it is an obstacle to effective TB control. Aims and Objectives: The study aims to study the prevalence of MDR-TB among new cases, retreatment cases and to study the rate of MDR-TB detection among suspected cases of Category I (CAT I) failure, CAT II failure and at the start of CAT II. Patients and Methods: The present retrolective study was conducted by reviewing the records of diagnosed MDR-TB patients at a drug-resistant TB center from January 2012 to December 2013. The data of new and retreatment pulmonary TB (PTB) cases diagnosed during that period were collected. The data were analyzed to find out the prevalence of MDR-TB, and the rate of MDR-TB detected among each CAT. Results: The prevalence of MDR-TB in new cases was $0.10 \%$ and that of retreatment cases was $4.3 \%$. The rate of MDR-TB detection among suspected cases of CAT I failure was $16.8 \%, 52.4 \%$ in CAT II failure, $11.6 \%$ at the start of CAT II, $11.7 \%$ among sputum positive during any month follow-up, $6.6 \%$ among MDR-TB contacts. Conclusion: Timely suspicion and diagnosis of MDR-TB and treatment are important in new and retreatment cases. All relapse or defaulter patients should be screened for MDR-TB at the start of CAT II treatment. MDR-TB should be suspected in any sputum-positive TB patient during treatment/sputum positive relapse/defaulter PTB.

Keywords: Isoniazid, multidrug-resistant directly observed therapy, rifampicin, tuberculosis

\section{INTRODUCTION}

Drug-resistant(DR) tuberculosis (TB) is known to occur since the introduction of anti-TB drugs. Multidrug-resistant (MDR-TB) has created a significant health problem in most of the countries, and it is an obstacle to effective TB control. ${ }^{[1]}$

According to the WHO 2016 update, there were 480,000 new cases of MDR-TB with 100,000 cases of rifampicin-resistant TB (RR-TB). The incidence of MDR-TB was 3.9\% in new cases and $21 \%$ in previously treated patients according to DR survey. ${ }^{[2]}$ The incidence has increased as compared to the WHO 2014 update. The incidence of MDR-TB was 3.5\% in new cases and $20.5 \%$ in previously treated patients. ${ }^{[3]}$ Globally, around 250,000 deaths occurred due to MDR/RR-TB in 2015, most of them from Asia. A total of 125,000 were enrolled on MDR-TB treatment in 2015 as compared to 97,000 patients enrolled in $2013 .{ }^{[2]} 52 \%$ of MDR/RR-TB patients enrolled on treatment in the year 2013 were reported to have been successfully treated and $17 \%$ died, $9 \%$ defaulted the treatment. ${ }^{[2]}$

\begin{tabular}{|l|l|}
\hline \multicolumn{2}{|c|}{ Access this article online } \\
\hline Quick Response Code: & Website: \\
\hline & www.ijrconline.org \\
\hline
\end{tabular}

India has second-highest burden of MDR-TB in the world after China with an estimated 99,000 new cases per year. The highest rates of MDR-TB were found in Nepal (48\%), Gujarat, India (33.8\%), New York City (30.1\%), Bolivia (15.3\%), and Korea $14.5 \% .{ }^{[4]}$ There are very limited data on the prevalence of MDR-TB in children. A study in African children has shown the prevalence of MDR-TB in children as $8.8 \%{ }^{[5]}$

Data from studies conducted by the National Institute of Research in TB and National TB Institute in India have shown the prevalence of MDR-TB $1 \%-3 \%$ in new cases and $12 \%$ in retreatment cases. ${ }^{[1]}$ The Revised National TB Control Programme (RNTCP) has undertaken DR survey studies in Gujarat, Maharashtra, and Andhra Pradesh estimated the

Address for correspondence: Dr. Supriya Dhakne Palwe, 408, "Anmol-Ghar Apartment", Professor Colony, Behind Racca's Green Square Lawns, Nashik - 422 003, Maharashtra, India. E-mail: drsupriyapalwefime2015@gmail.com

This is an open access journal, and articles are distributed under the terms of the Creative Commons Attribution-NonCommercial-ShareAlike 4.0 License, which allows others to remix, tweak, and build upon the work non-commercially, as long as appropriate credit is given and the new creations are licensed under the identical terms.

For reprints contact: reprints@medknow.com

How to cite this article: Kulkarni GS, Palwe SD, Patil NP, Telkhade AJ, Kadukar J. Prevalence of multidrug-resistant tuberculosis at a regional drug-resistant tuberculosis center of Maharashtra. Indian J Respir Care 2020;9:30-4.

Received: 02-04-2019 Accepted: $20-07-2019$
Revised: $20-05-2019$ Published: $08-01-2020$ 
prevalence of MDR-TB 3\% in new cases and $12 \%-17 \%$ in retreatment cases. ${ }^{[1]}$

There have been previous studies conducted regarding the prevalence of MDR-TB in new and re-treatment cases. However, very few studies have been conducted to detect the rate of MDR-TB in category (CAT)-wise failures. The present study was done with an aim to study the prevalence of MDR-TB among new cases and retreatment cases. It also aimed to study the rate of MDR-TB detection among suspected cases of CAT I a failure, CAT II failure, and at the start of CAT II.

\section{Patients and Methods}

The present retrolective study was conducted by reviewing the records at the Regional DR TB center, Nashik, Maharashtra, India. This regional center caters to patients from Nashik, Jalgaon, Dhule, Nandurbar, and Malegaon. Patients who satisfied the inclusion criteria from January 2012 to December 2013 were studied.

The patients included were all registered pulmonary TB (PTB) patients at regional directly observed treatment short-course (DOTS) center and all those who were diagnosed MDR-TB patients by line probe assay at regional DOTS center and referred to DR-TB center Nashik. Patients having other medical conditions causing breathing difficulties (e.g., pulmonary edema, and ARDS), coronary heart diseases, diabetes mellitus, and hypertension were excluded from the study.

The records of diagnosed MDR-TB patients at DR-TB center and their previous TB treatment records were also reviewed. The data of MDR suspects among CAT I failure, CAT II positive at diagnosis, and CAT II failure were reviewed. Patients were categorized according to RNTCP criteria for initiation of MDR-TB, i.e., CAT I failure, CAT II positive at diagnosis, CAT II failure, and any follow-up sputum positive. The data of new and retreatment PTB cases diagnosed during that period were collected. The data were analyzed to find out the prevalence of MDR-TB and the rate of MDR-TB in each CAT.

For the present study, the following case definitions ${ }^{[1]}$ were used:

- New case: A TB patient who never had treatment for TB or has taken anti-TB drugs for less 1 month

- Retreatment case: CAT II includes all retreatment cases, i.e., relapse, failure, treatment after default, and others

- $\quad$ CAT I failure: Any TB patient who is sputum positive at 5 months or more after starting CAT I treatment

- $\quad$ CAT II failure: Any TB patient who is sputum positive at 5 months or more after starting CAT II treatment

- MDR-TB Case: An MDR-TB suspect who is bacteriologically confirmed of TB and has Mycobacterium tuberculosis resistant to isoniazid and rifampicin, with or without resistance to other anti-TB drugs based on drug sensitivity testing (DST) results from an RNTCP accredited laboratory.

\section{RESULTS}

The total number of TB cases diagnosed during this period were 25,191, out of which 318 (1.26\%) were MDR-TB. The prevalence of MDR-TB in new cases is $0.10 \%$, i.e., out of 20000 new cases, 21 had MDR-TB. Out of 5191, retreatment cases, $236(4.3 \%)$ were detected to have MDR-TB [Table 1].

Table 2 shows that out of 318 MDR-TB patients, 21 (6.1\%) were CAT I failure, 43 (13.52\%) were CAT II failure, 49 (15.40\%) were any follow-up sputum positive, 193 (60.70\%) were at the start of CAT II to have MDR-TB.

The study shows that the maximum number of MDR-TB patients were in economically productive age group (15-55 years). Out of 318, 210 were male and 108 were female [Figure 1].

Of 125 CAT I failure (i.e., sputum positive at 4 months), $21(16.8 \%)$ MDR-TB were detected. Out of 82 CAT II failures, 43 (52.4\%) MDR-TB cases were detected. At the start of CAT II, 1653 were suspected MDR and 193 (11.6\%) were detected to have MDR-TB. It was also found from RNTCP record that 30 contacts of known MDR were suspected MDR and 2 (6.6\%) were detected MDR-TB. At CAT II diagnosis, 68 sputum-negative patients were suspected MDR and 3 (4.4\%) detected MDR-TB. Four hundred and eighteen patients were suspected MDR who were found to be sputum positive during any month follow-up in CAT I and

\begin{tabular}{lccc}
\hline $\begin{array}{l}\text { Table 1: Multidrug-resistant tuberculosis prevalence in } \\
\text { new (Category I) and retreatment }\end{array}$ & (category II) & cases \\
\hline TB cases & $\boldsymbol{n}$ & $\begin{array}{c}\text { MDR-TB } \\
\text { detected }\end{array}$ & $\begin{array}{c}\text { Prevalence of } \\
\text { MDR TB (\%) }\end{array}$ \\
\hline New (Category I) & 20,000 & 21 & 0.10 \\
Retreatment (Category II) & 5191 & 236 & 4.5 \\
Total & 25,191 & 318 & 1.26 \\
\hline
\end{tabular}

MDR-TB: Multidrug-resistant tuberculosis

\begin{tabular}{lc}
\hline Table 2: Distribution of multidrug-resistant tuberculosis \\
cases according to the Revised National Tuberculosis \\
Control Programme criteria at initiation of Category IV at \\
drug-resistant tuberculosis Centre, Nashik \\
\hline Criteria \\
\hline Criteria A \\
$\quad$ Category I failure \\
$\quad$ Category II positive at 4 months or later \\
$\quad$ MDR-TB contact - sputum-positive pulmonary TB \\
Criteria B \\
$\quad \begin{array}{l}\text { Sputum positive retreatment at start of Category II } \\
\text { (relapse, defaulter) }\end{array}$ \\
$\quad$ Any follow-up sputum positive \\
$\begin{array}{l}\text { Criteria C } \\
\text { Sputum negative retreatment at start of Category II }\end{array}$ \\
$\begin{array}{l}\text { Category IV defaulters (rediagnosed) } \\
\text { Suspected Category IV failure }\end{array}$ \\
$\begin{array}{l}\text { Total } \\
\text { MDR-TB: Multidrug-resistant tuberculosis }\end{array}$ \\
\end{tabular}




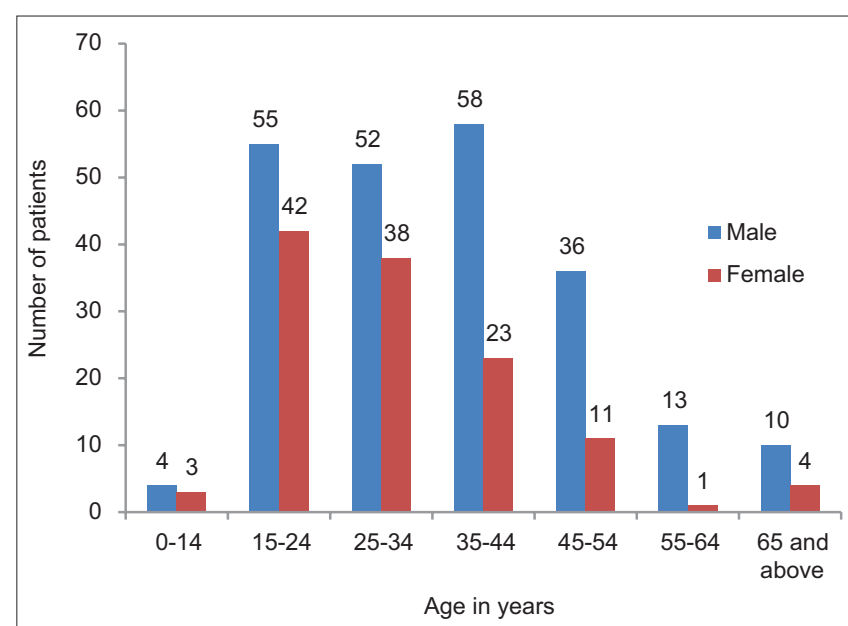

Figure 1: Age and sex distribution of study subjects

CAT II, out of 418 MDR was detected in 49 (11.7\%) [Table 3 and Figure 2].

\section{Discussion}

MDR-TB is a manmade phenomenon. The use of inadequate regimens, poor adherence to treatment, inappropriate DOTS leads to increase in the DR levels in the community. Undiagnosed and improperly treated patients with resistant strains of TB are a source of ongoing transmission of resistant strains.

India, being a resource-limited country; there are constraints on the availability and affordability of DST facilities. Hence, much of the anti-TB drug resistance is diagnosed presumptively based on the lack of response to treatment or relapse of symptoms in patients.

The present study has found very low prevalence of MDR-TB, namely $0.10 \%$ in new TB cases and $4.3 \%$ in retreatment cases, as compared to other Indian studies, as shown in Table 4.

The proportion of MDR-TB cases among new cases and retreatment cases reported globally from 1994 to 2009 ranged from $0 \%$ to $28.3 \%$ and $0 \%$ to $61.6 \%$, respectively. ${ }^{[7]}$ Although the present study has large sample size and representative of the population at large, the present study has large sample size and is representative of the population at large. However, the limitation of the study is that all new and retreatment cases were not subjected to DST due to the limitation of resources. Only suspected patients, i.e., CAT I failure and CAT II failure were subjected to DST. This could be the most probable reason for the low prevalence of MDR-TB in the present study.

The study conducted by Almeida et al..$^{[11]}$ at Mumbai shows MDR-TB prevalence as $24 \%$. The study conducted by Mistry et al..$^{[12]}$ also suggest that MDR-TB prevalence is higher in Mumbai than any other part of India, having 24\%-30\% in new cases and $11 \%-67 \%$ in treated cases ${ }^{[12]}$ These rates of resistance in Mumbai are among highest reported worldwide. Major reason for this may be the highly variable treatment prescribed

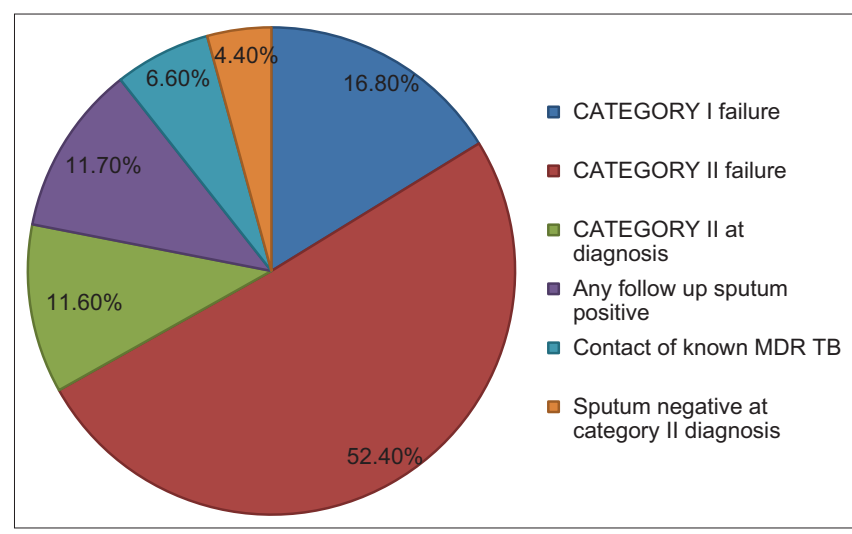

Figure 2: Categories of multidrug-resistant tuberculosis cases

\begin{tabular}{|c|c|c|}
\hline MDR-TB suspect criteria & $\begin{array}{l}\text { MDR-TB } \\
\text { suspected }\end{array}$ & $\begin{array}{c}\text { MDR-TB } \\
\text { detected, } n(\%)\end{array}$ \\
\hline Total & 2419 & $318(13.14)$ \\
\hline Category I failure & 125 & $21(16.8)$ \\
\hline Category II failure & 82 & $43(52.4)$ \\
\hline Category II at diagnosis & 1653 & $193(11.6)$ \\
\hline Any follow-up sputum positive & 418 & 49 (11.7) \\
\hline Contact of known MDR-TB & 30 & $2(6.6)$ \\
\hline Sputum negative at category II diagnosis & 68 & $3(4.4)$ \\
\hline
\end{tabular}

MDR-TB: Multidrug-resistant tuberculosis

Table 4: Comparison of prevalence of multidrug-resistant tuberculosis in the present study to previous studies

\begin{tabular}{|c|c|c|}
\hline Study & $\begin{array}{c}\text { MDR-TB } \\
\text { prevalence in } \\
\text { new cases (\%) }\end{array}$ & $\begin{array}{l}\text { MDR-TB prevalence } \\
\text { in re-treatment } \\
\text { cases }(\%)\end{array}$ \\
\hline Present study & 0.10 & 4.3 \\
\hline PMDT guidelines ${ }^{[1]}$ & & $12-17$ \\
\hline Paramasivan $\mathrm{CN}^{[6]}$ & $0.14-5.3$ & \\
\hline Cohn et al..$^{[7]}$ & $0-28.3$ & $0-61.6$ \\
\hline Sharma et al. ${ }^{[8]}$ & & 1.1 \\
\hline Angrup et al. ${ }^{[9]}$ & & $5-12.7$ \\
\hline Datta et al.$^{[10]}$ Kashmir & & 5.75 \\
\hline Almeida et al.$^{[1]}$ Mumbai & & 24 \\
\hline Mistry et al..$^{[12]}$ & $24-30$ & $11-67$ \\
\hline
\end{tabular}

by doctors in Mumbai's private sector, overcrowding, HIV infection. ${ }^{[1]}$ Hence, they have recommended operational research to find out the prevalence of MDR-TB in CAT I failure and CAT II failure. ${ }^{[12]}$

The present study shows that among MDR-TB patients maximum were diagnosed at the start of CAT II treatment. These are the patients who have already taken anti-TB treatment before. A comparison with other studies is given in Table 5 . A study by Kandi et al. ${ }^{[16]}$ observed that every three patients among 10 retreatment patients develop MDR-TB. 
Kulkarni, et al:: MDR-TB prevalence at a DR-TB center

\begin{tabular}{lcccc}
\hline \multicolumn{5}{l}{ Table 5: Comparison of categories of multidrug-resistant tuberculosis at diagnosis } \\
\hline Categories of MDR-TB cases & Present study & Mostafizur Rahman et al. ${ }^{[13]}$ & Devesh Pratap Singh et al. ${ }^{[14]}$ & Abdul Ghafoor et al.. ${ }^{[15]}$ \\
\hline Category I failure (\%) & 16.8 & 13 & 44.4 & 30.3 \\
Category II failure (\%) & 52.4 & 87 & 63.38 & 28.79 \\
At the start of Category II (\%) & 11.6 & & & 40.91 \\
\hline
\end{tabular}

MDR-TB: Multidrug-resistant tuberculosis

All the above studies, including the present study, are suggestive of higher prevalence of MDR-TB in CAT II failure. Hence, all sputum-positive patients at the diagnosis of CAT II should be screened for MDR-TB. Furthermore, any sputum-positive patient, either at the start of treatment or during follow-up, should be suspected for MDR-TB. According to Burugina Nagaraja et al., ${ }^{[17]}$ treatment outcome of a patient who fails first-line ATT and not given MDR regimen is poor. Hence, the authors recommend that MDR regimen should be given to DR TB other than MDR-TB.

In the present study, MDR-TB was more prevalent among male patients as compared to female patients. The maximum numbers of patients were in the economically productive age group. This explains the direct and indirect costs involved in MDR-TB treatment.

MDR-TB is a major public health problem in developing and developed countries. MDR-TB levels are higher in areas with poor TB control, and the proportion of retreatment cases is high. The causes of MDR-TB are disease-related, patient-related, and physician-related. The most common causes of MDR-TB are inappropriate regimen, inadequate duration, inadequate and irregular drug intake, irregular follow-up till treatment completion, delayed diagnosis of MDR-TB, non-affordability for diagnosis, and treatment. The study from China by Liang et al. ${ }^{[18]}$ shows financial burden, poor knowledge, side effects of treatment, lack of coordination of services, unsatisfactory supervision of treatment are a contributory factor for MDR-TB. However, inappropriate treatment is the most important factor.

Due to nonaffordability most of the private patients do not complete first-line ATT, cannot undergo DST for diagnosis of MDR and MDR treatment. MDR-TB patients live for number of years before succumbing to the disease. Hence, these undiagnosed MDR patients, diagnosed but refused MDR treatment, MDR defaulters, improperly treated MDR patients are the source of ongoing transmission of resistant strains. Many undiagnosed MDR patients treated with first-line anti-TB drugs/Short Course Chemotherapy causes amplifier effect. When Short Course Chemotherapy is used continuously over a long period in MDR patients, the resistant strains in the bacterial population are selected repeatedly and these become the dominant strains and leads to the development of MDR-TB ${ }^{[1]}$ Similar findings have been reported by Dholakia and Shah ${ }^{[19]}$ study shows that out of 24 MDR-TB patients 14 had resistant to other first-line drugs suggest probable amplification of resistance by CAT II regimen which was received by the patient.

\section{Conclusion}

Any previously treated PTB patient who develops sputum-positive TB again should not be labeled as relapse or defaulter. All patients should be screened for MDR-TB at the start of CAT II. Timely diagnosis of MDR-TB and treatment is important in new cases. In addition, there is a need to change the regimen for CAT I. MDR-TB should be screened in any sputum-positive TB patient during treatment/relapse/defaulter. It is very important to prevent the emergence of MDR-TB rather than its treatment. Good quality DOTS program should be the first priority for TB control.

\section{Financial support and sponsorship}

Nil.

\section{Conflicts of interest}

There are no conflicts of interest.

\section{REFERENCES}

1. Central TB Division, Directorate General of Health Services, Ministry of Health and Family Welfare, Nirman Bhavan. Guidelines on Programmatic Management of Drug Resistant TB in India. New Delhi: Central TB Division, Directorate General of Health Services, Ministry of Health and Family Welfare, Nirman Bhavan; 2012.

2. WHO Treatment Guidelines for Drug Resistant Tuberculosis. 2016 Update. Annexes 4.5 \& 6. The End TB Strategy. World Health Organization, 2016.

3. Varaine F, Rich M. Tuberculosis- Practical Guide for Clinicians, Nurses, Laboratory Technicians and Medical Auxillaries. 2014 Edition. Medicines Sans Frontiers \& Partners in Health Publication; 2014.

4. Dye C, Espinal MA, Watt CJ, Mbiaga C, Williams BG. Worldwide incidence of multidrug-resistant tuberculosis. $\mathrm{J}$ Infect Dis 2002;185:1197-202.

5. Fairlie L, Beylis NC, Reubenson G, Moore DP, Madhi SA. High prevalence of childhood multi-drug resistant tuberculosis in Johannesburg, South Africa: A cross sectional study. BMC Infect Dis 2011;11:28.

6. Paramasivan $\mathrm{CN}$. An overview on drug resistant TB in India. Indian J Tuberc 1998;45:73-81.

7. Cohn DL, Bustero F, Raviglion MC. Drug resistant TB review of the worldwide situation and the WHO/IUATLD Global surveillance project. Clin Infect Dis 1997;24:121-30.

8. Sharma SK, Kaushik G, Jha B, George N, Arora SK, Gupta D, et al. Prevalence of multidrug-resistant tuberculosis among newly diagnosed cases of sputum-positive pulmonary tuberculosis. Indian J Med Res 2011;133:308-11.

9. Angrup A, Varma-Basil M, Kumar S, Pathak RK, Sharma H, Banavaliker JN. Drug resistance among Mycobacterium tuberculosis isolates from private clinics and a dots center in Delhi, India. Southeast Asian J Trop Med Public Health 2011;42:122-7.

10. Datta BS, Hassan G, Kadri SM, Qureshi W, Kamili MA, Singh H, et al. Multidrug-resistant and extensively drug resistant tuberculosis in Kashmir, India. J Infect Dev Ctries 2009;4:19-23.

11. Almeida D, Rodrigues C, Udwadia ZF, Lalvani A, Gothi GD, Mehta P, et al. Incidence of multidrug-resistant tuberculosis in urban and rural 
India and implications for prevention. Clin Infect Dis 2003;36:e152-4.

12. Mistry N, Tolani M, Osrin D. Drug-resistant tuberculosis in Mumbai, India: An Agenda for operations research. Oper Res Health Care 2012;1:45-53.

13. Rahman M, Kamal S, Mohammed F, Alam M, Ahasan H. Anti-tuberculosis drug resistance pattern among different category of tuberculosis patients. J Med 2009;10:45-7.

14. Singh DP, Kumar S, Singh GV, Gupta RK, Chauhan DS, Amir Mohammad A. Multidrug resistant (MDR) tuberculosis in MDR suspect patients and assessment of various reasons for developing drug resistance. Indian J Sci Res Technol 2015;3:26-30.

15. Ghafoor A, Mehraj J, Afridi ND, Rafiq Y, Wendl-Richter HU, Hasan R. Multidrug resistant Mycobacterium tuberculosis amongst category I and II failures and category II relapse patients from Pakistan. Int J Mycobacteriol 2012;1:118-23.
16. Kandi S, Prasad SV, Sagar Reddy PN, Reddy VC, Laxmi R, Kopuu D et al. Prevalence of multidrug resistance among retreatment pulmonary tuberculosis cases in a tertiary care hospital, Hyderabad, India. Lung India 2013;30:277-9.

17. Burugina Nagaraja S, Satyanarayana S, Chadha SS, Kalemane S, Jaju J, Achanta S, et al. How do patients who fail first-line TB treatment but who are not placed on an MDR-TB regimen fare in South India? PLoS One 2011;6:e25698.

18. Liang L, Wu Q, Gao L, Hao Y, Liu C, Xie Y, et al. Factors contributing to the high prevalence of multidrug-resistant tuberculosis: A study from China. Thorax 2012;67:632-8.

19. Dholakia YN, Shah DP. Clinical profile and treatment outcomes of drug-resistant tuberculosis before directly observed treatment strategy plus: Lessons for the program. Lung India 2013;30:316-20. 